\title{
Modulating the Sensory Response of a Conjugated Polymer by Proteins: An Agglutination Assay for Mercury Ions in Water
}

\author{
Ik-Bum Kim and Uwe H. F. Bunz* \\ School of Chemistry and Biochemistry, Georgia Institute of Technology, 770 State St., \\ Atlanta, GA 30332, USA. Fax: 01(404)385-1795; Tel: 01(404)385-1795; E-mail: \\ uwe.bunz@chemistry.gatech.edu
}

\section{Supporting Information (SI)}

Instrumentation and Materials. All chemicals and solvents were used without further purification as received unless otherwise noted. Histone (from calf thymus, Type II-A), papain (from Papaya Latex), albumin (from bovine serum, BSA), Myosin (from rabbit muscle), and Adenosine 5'-triphosphate disodium salt were purchased from Sigma Chemical Co. Poly(diallydimethylammonium chloride) (Pdac, $\mathrm{Mw}=400,000-500,000)$ was purchased from Aldrich Co. Fluorescence data were obtained with a Shimadzu RF-5301PC spectrofluorophotometer in quartz cuvettes. PPE $\underline{1}$ was synthesized according to the previous report ${ }^{1}$ and had the number average molecular weight of 12,000 with a polydispersity $(\mathrm{Mw} / \mathrm{Mn})$ of 4.3. The excitation wavelength was $425 \mathrm{~nm}$ and the emission was recorded from $440 \mathrm{~nm}$ to $650 \mathrm{~nm}$. The absorption maximum of solutions of $\underline{1}$ was at $428 \mathrm{~nm}$. Solutions of PPE $\underline{1}$ were prepared in $0.1 \mathrm{M}$ sodium phosphate buffer $(\mathrm{pH}=7.2)$. Concentrations of PPE 1 were adjusted to $5 \times 10^{-6} \mathrm{M}$ on the basis of the molecular weight of the repeating unit of PPE $\underline{1}$. Concentrations of all stock protein solutions were adjusted to $2.5 \mathrm{mM} .10 \mu \mathrm{L}$ of each protein solution was added to $5 \mathrm{~mL}$ of a solution of PPE $\underline{1}$ in a vial. The final concentration of protein was $5 \times 10^{-6} \mathrm{M}$ in the experiments. In each quenching experiment, a small aliquot $(20-100 \mu \mathrm{L})$ of concentrated quencher solution was added to $5 \mathrm{~mL}$ of diluted fluorophore solution by using a calibrated microliter pipet. The fluorescence was recorded at room temperature.

Scheme 1. Synthesis of Amine-Substituted PPE $\underline{\mathbf{5}}$

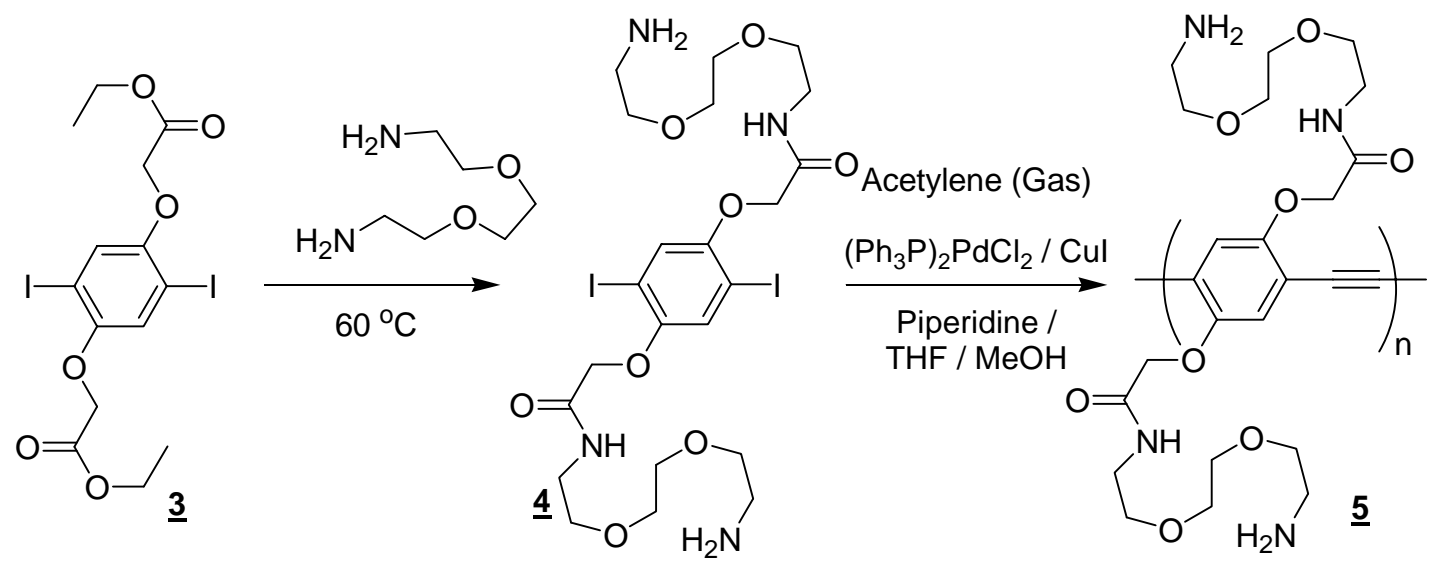


Synthesis of Monomer (4) : A mixture of the ester $\underline{3}(5.34 \mathrm{~g}, 10.0 \mathrm{mmol})$ and 1,2-bis(2aminoethoxy)ethane $(40.4 \mathrm{~g}, 273 \mathrm{mmol})$ was placed in a $100 \mathrm{~mL}$ round bottom flask and heated to $60^{\circ} \mathrm{C}$ with magnetic stirring for $16 \mathrm{~h}$. Ethanol $(50 \mathrm{~mL})$ was added to the reaction mixture. The precipitate was collected on a glass filter and washed with ethanol. The product was dried under reduced pressure and a colorless solid $\underline{4}(6.20 \mathrm{~g}, 94 \%)$ was obtained. ${ }^{1} \mathrm{H}$ NMR (DMSO-d $\left.\mathrm{d}_{6}\right): \delta$ $7.30(\mathrm{~s}, 2 \mathrm{H}), 4.52(\mathrm{~s}, 4 \mathrm{H}), 3.50(\mathrm{~m}, 12 \mathrm{H}), 3.31(\mathrm{~m}, 8 \mathrm{H}), 2.61(\mathrm{t}, 4 \mathrm{H}) .{ }^{13} \mathrm{C}$ NMR (DMSO-d 6 ): $\delta$ 167.06, 152.12, 123.04, 86.79, 73.10, 69.66, 69.58, 68.91, 68.77, 41.35, 38.36. IR: v 3413, 2864, $1658,1541,1483,1427,1352,1217,1134,1080,850$. MP : $169-170{ }^{\circ} \mathrm{C}$.

Synthesis of Polymer (ㅁ): Monomer $\underline{4}(1.03 \mathrm{~g}, 1.40 \mathrm{mmol})$ was dissolved in a mixture of piperidine $(1 \mathrm{~mL})$, THF $(2 \mathrm{~mL})$, and methanol $(2 \mathrm{~mL})$ in a Schlenk flask $(25 \mathrm{~mL})$ under a flow of nitrogen and with magnetic stirring. $\left(\mathrm{Ph}_{3} \mathrm{P}\right)_{2} \mathrm{PdCl}_{2}(2.0 \mathrm{mg}, 2.8 \mu \mathrm{mol})$ and $\mathrm{CuI}(0.5 \mathrm{mg}, 2.8$ $\mu \mathrm{mol})$ were added to the flask and the contents were treated with acetylene gas according to reference ${ }^{2}$. The reaction mixture was stirred at the room temperature for $24 \mathrm{~h}$. The solution was slowly added to ether $(200 \mathrm{~mL})$. The precipitate was washed with acetone. An orange solid was obtained in $99 \%$ yield $\left(702 \mathrm{mg}\right.$ ). ${ }^{1} \mathrm{H}$ NMR (DMSO-d 6 ): $\delta 7.19(\mathrm{~s}, 2 \mathrm{H}), 4.66(\mathrm{~s}, 4 \mathrm{H}), 3.56-3.31$, 2.99. IR: $v 3620,3413,2867,1679,1537,1215,1139,1051,865$. Due to lack of solubility, ${ }^{13} \mathrm{C}$ NMR spectrum could not be offered.

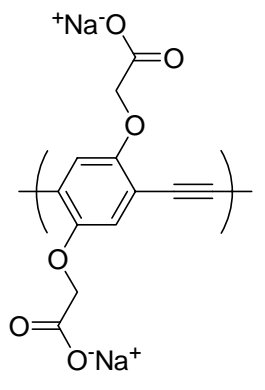

$\underline{1}$

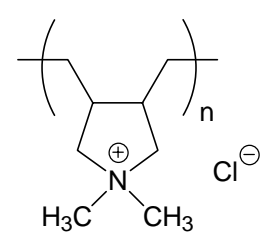

$\underline{2}$

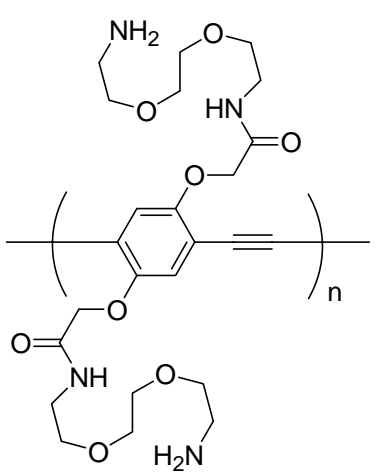

$\underline{5}$

Figure 1. Structures of Carboxylate-Substituted PPE (1). Poly(diallydimethylammonium chloride) (Pdac, 2), and Amine-Substituted PPE (모) for sensing experiments.

Experiment 1. Influence of 10 different metal ions on the optical properties of $\underline{1}$ in $0.1 \mathrm{M}$ phosphate buffer at $\mathbf{p H}=7.2$.

To investigate the sensory ability of $\underline{\mathbf{1}}$ (Exp. 1) and complex polymers (Exp. 2) toward metal ions, we exposed them to concentrated solutions of metal ions in $0.1 \mathrm{M}$ phosphate buffer solution $(\mathrm{pH}=7.2)$. Concentrations of PPE $\underline{\mathbf{1}}$ were adjusted to $5 \times 10^{-6} \mathrm{M}$ on the basis of the molecular weight of the repeating unit of PPE $\underline{1}$. Solutions of 10 metal compounds are prepared in $0.1 \mathrm{M}$ concentration: They are $\mathrm{Zn}\left(\mathrm{ClO}_{4}\right)_{2}, \mathrm{CdCl}_{2}, \mathrm{Hg}\left(\mathrm{O}-\mathrm{CO}-\mathrm{CF}_{3}\right)_{2}, \mathrm{~Pb}\left(\mathrm{NO}_{3}\right)_{2}, \mathrm{FeCl}_{3}, \mathrm{NiCl}_{2}, \mathrm{CoCl}_{2}$, $\mathrm{CuBr}_{2}, \mathrm{Ca}\left(\mathrm{NO}_{3}\right)_{2}$, and $\mathrm{Mg}(\mathrm{OTf})_{2} .20 \mu \mathrm{L}$ of each metal ion solution was added to $5 \mathrm{~mL}$ of a buffered solution of $\underline{1}$ in a vial. The concentration of each metal ion is $4 \times 10^{-4} \mathrm{M}$ in a buffered solution of $\underline{\mathbf{1}}$. The fluorescence spectra are shown in Figure $\mathbf{2}$ and a picture was taken on the 
samples under the irradiation of UV lamp (see Figure 3). Most metal cations showed slight effects while mercury showed the substantial quenching of the fluorescence at a concentration of $4 \times 10^{-4} \mathrm{M}$. While $\mathrm{Pb}$ and $\mathrm{Hg}$ ions showed mild quenching in diluted solution of $\underline{\mathbf{1}}^{1}, \mathrm{Hg}$ ions showed large quenching in concentrated solution of $\underline{1}$ after certain periods of time.

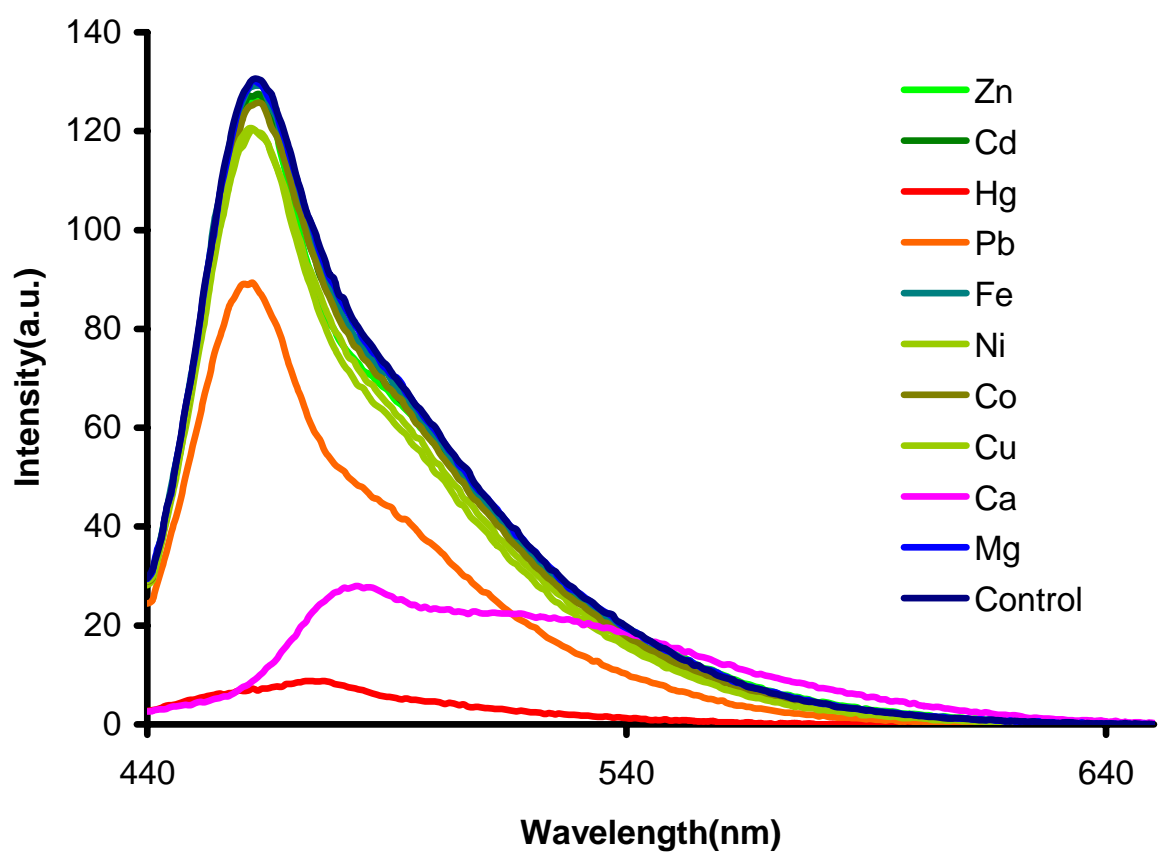

Figure 2. Emission spectra of solutions of PPE $\underline{1}$ by addition of $20 \mu \mathrm{L}$ of a $0.4 \mathrm{mM}$ solution of metal ions. Spectra show significant red shift with $\mathrm{Ca}$ ions and quenching with $\mathrm{Hg}$ ions.

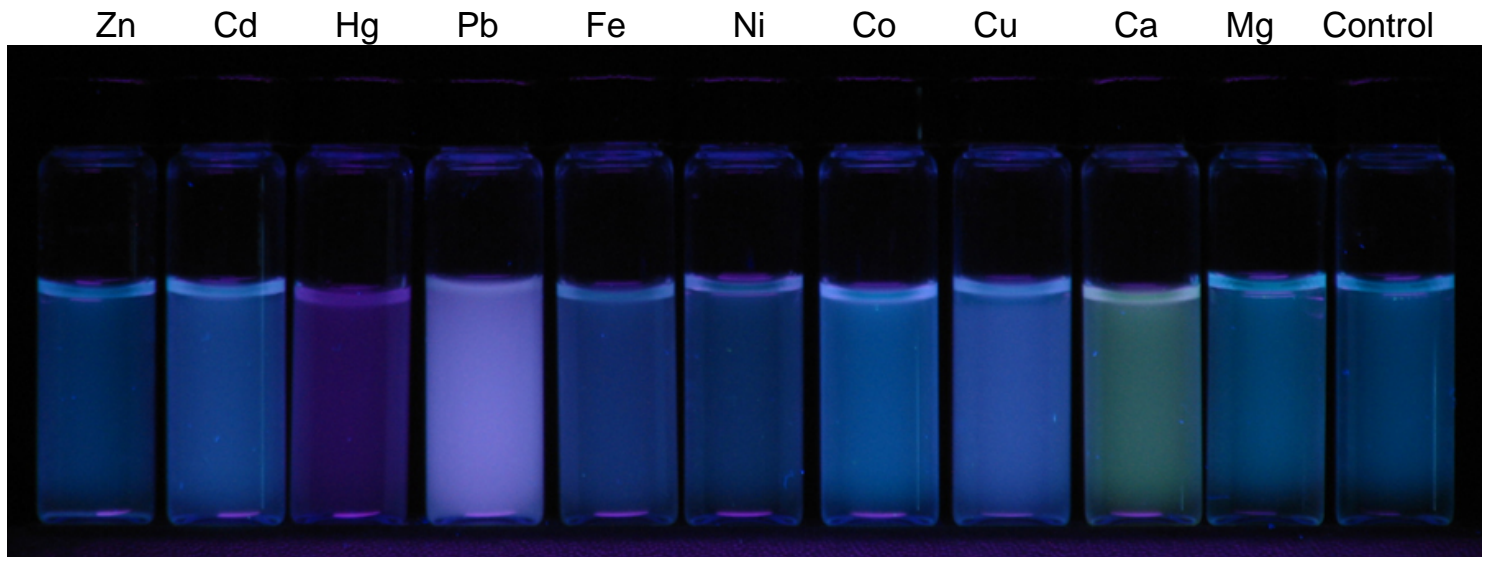

Figure 3. Fluorescence of PPE 1 in the presence of metal ions. Addition of lead ions led to a turbid solution, but showed mild quenching of the fluorescence. Ca ions showed yellow color emission. (366 nm excitation) 


\section{Experiment 2. Influence of metal ions on the optical properties of the polymer 1 in the presence of a) Pdac, b) Histone, c) BSA, and d) Papain.}

Exp. 2a) Influence of metal ions on the optical properties of the polymer 1 in the presence of Pdac. The concentration of Pdac used in this experiment is $2.5 \times 10^{-5} \mathrm{M}$. In the PPE 1-Pdac complex, we observed a red shift and an increase of fluorescence. The addition of each metal ion to the polymer complex leads to some quenching of the fluorescence. The concentration of each metal ion is $4 \times 10^{-4} \mathrm{M}$ in a buffered solution of the PPE $\mathbf{1}$-Pdac complex. $\mathrm{Hg}, \mathrm{Pb}$, and $\mathrm{Cd}$ ions show mild quenching, while $\mathrm{Fe}$ and $\mathrm{Cu}$ ions show some quenching. The emission data were taken from samples that were photographed. While in the photo the effects are less visible, the spectra are clearly shown to support our interpretations. This is an issue of the color resolution of the used camera, not the sample response. The digital camera used for the photographs was Cannon Powershot Pro 1 with 8 megapixels of imaging power.

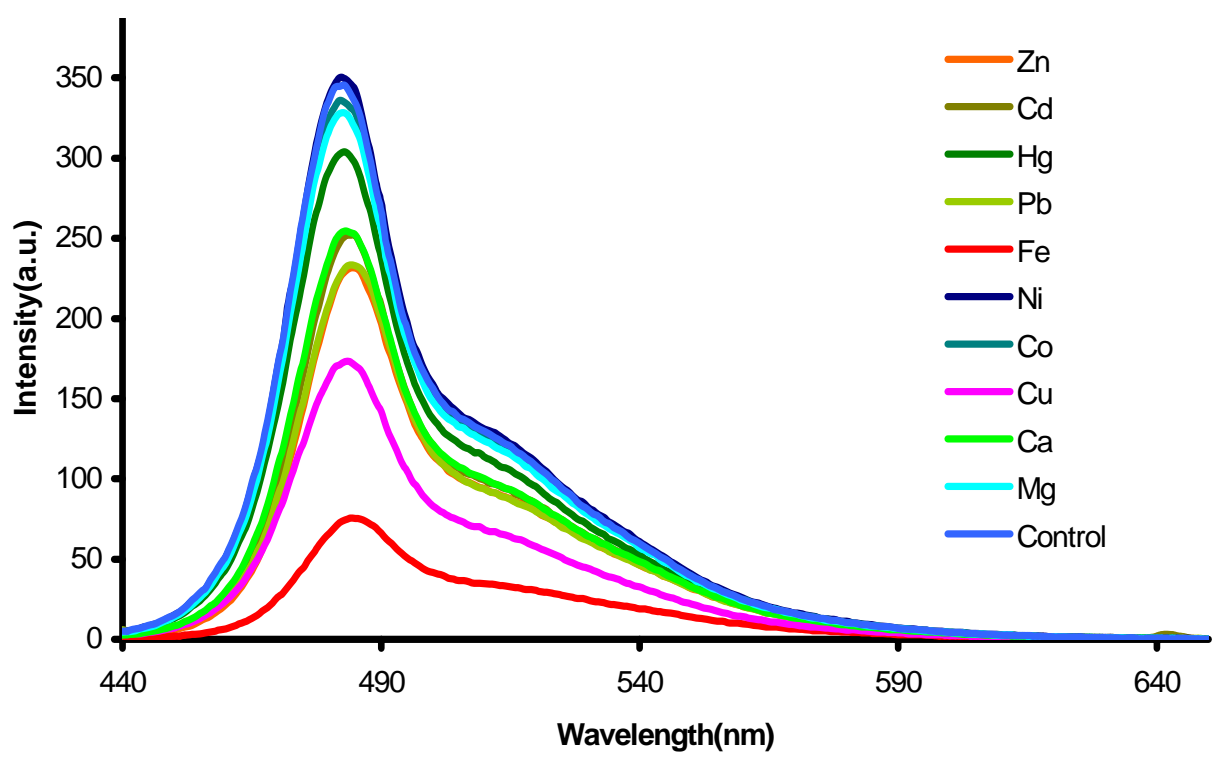

Figure 4. Emission spectra of solutions of the PPE 1-Pdac complex by addition of metal ions. Fe ions led to the largest quenching among 10 metal ions. $\mathrm{Hg}$ and $\mathrm{Ca}$ ions did not change the optical property of the complex.

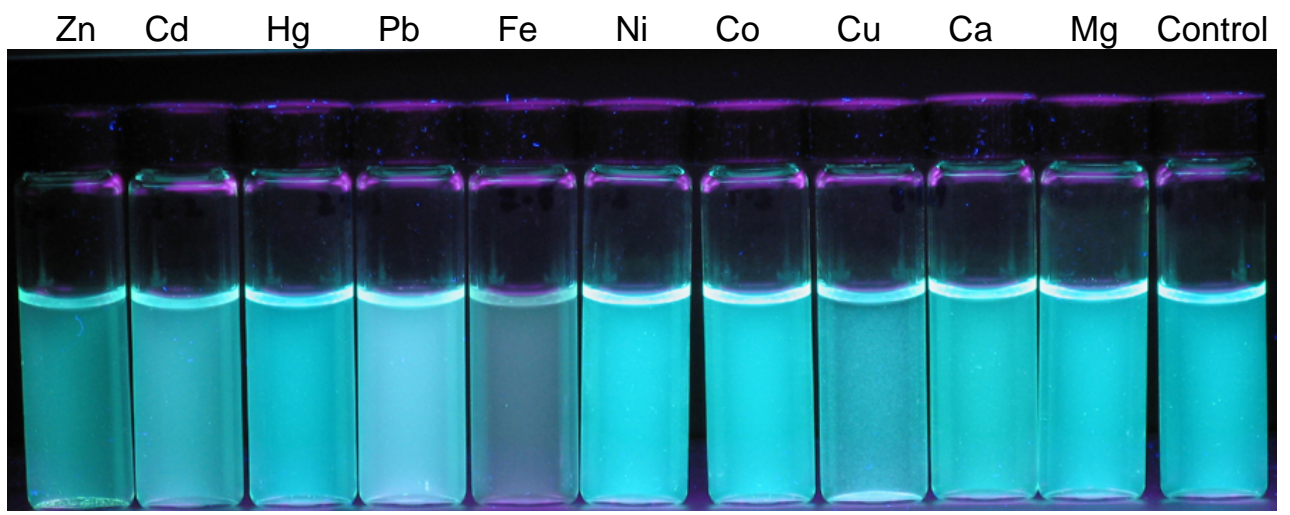

Figure 5. Fluorescence of PPE 1-Pdac complex upon in aqueous buffer the addition of different metal ions. (366 $\mathrm{nm}$ excitation) 
Exp. 2b) Influence of metal ions on the optical properties of the polymer 1 in the presence of histone.

$10 \mu \mathrm{L}$ of histone solution was added to $5 \mathrm{~mL}$ of a solution of PPE $\underline{\mathbf{1}}$. The concentration of histone used in this experiment is $5 \times 10^{-6} \mathrm{M}$. The mixture in a vial was shaken to give the PPE 1histone complex. In the PPE 1-histone complex, mercury ions led to significant effect on the fluorescence at the concentration of $4 \times 10^{-4} \mathrm{M}$ while other metal ions show mild quenching.

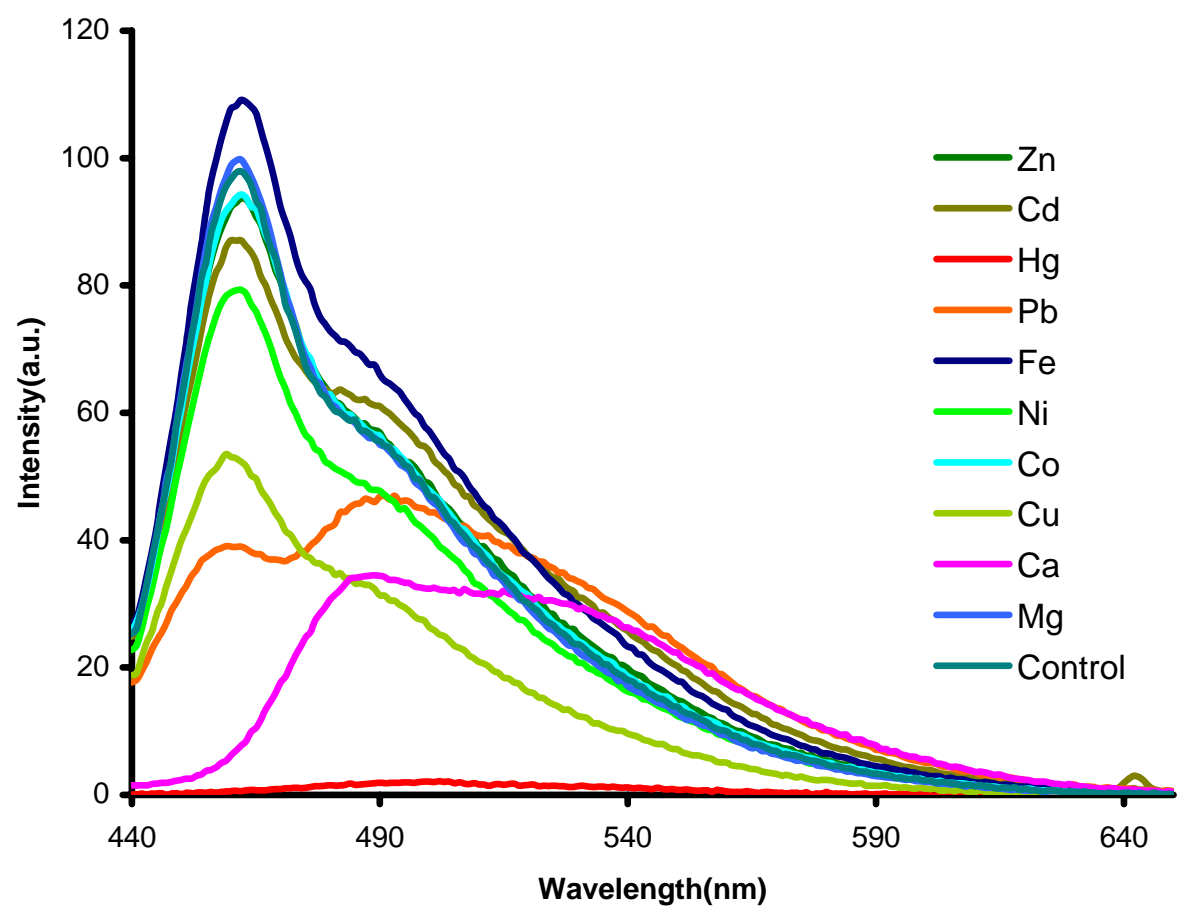

Figure 6. Emission spectra of solutions of the PPE 1-histone complex by addition of metal ions. Mercury ions led to disappearance of fluorescence while $\mathrm{Cu}, \mathrm{Pb}$, and $\mathrm{Ca}$ ions showed mild quenching under aggregation and red shift of emission.

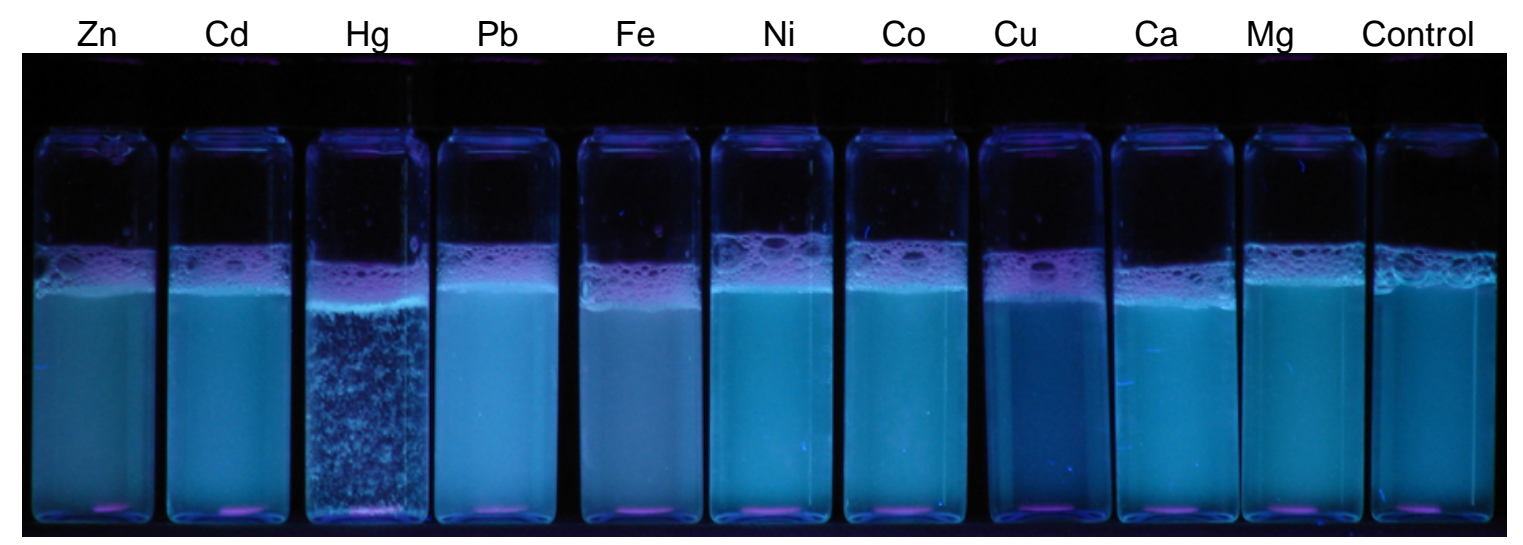

Figure 7. Fluorescence of the PPE 1-histone complex in aqueous buffer upon addition of metal ions. Agglutination for mercury ions with the complex was observed. Ca ions led to a red shift in its emission spectrum and visible by the naked eye, but difficult to discern in the picture. (366 nm excitation) 
Exp. 2c) Influence of metal ions on the optical properties of 1 in the presence of BSA.

Concentration of BSA used in this experiment is $5 \times 10^{-6} \mathrm{M}$. In the PPE 1-BSA complex, mercury ions led to significant quenching of the fluorescence at the concentration of $4 \times 10^{-4} \mathrm{M}$ while $\mathrm{Cu}$ and $\mathrm{Ca}$ ions show some quenching.

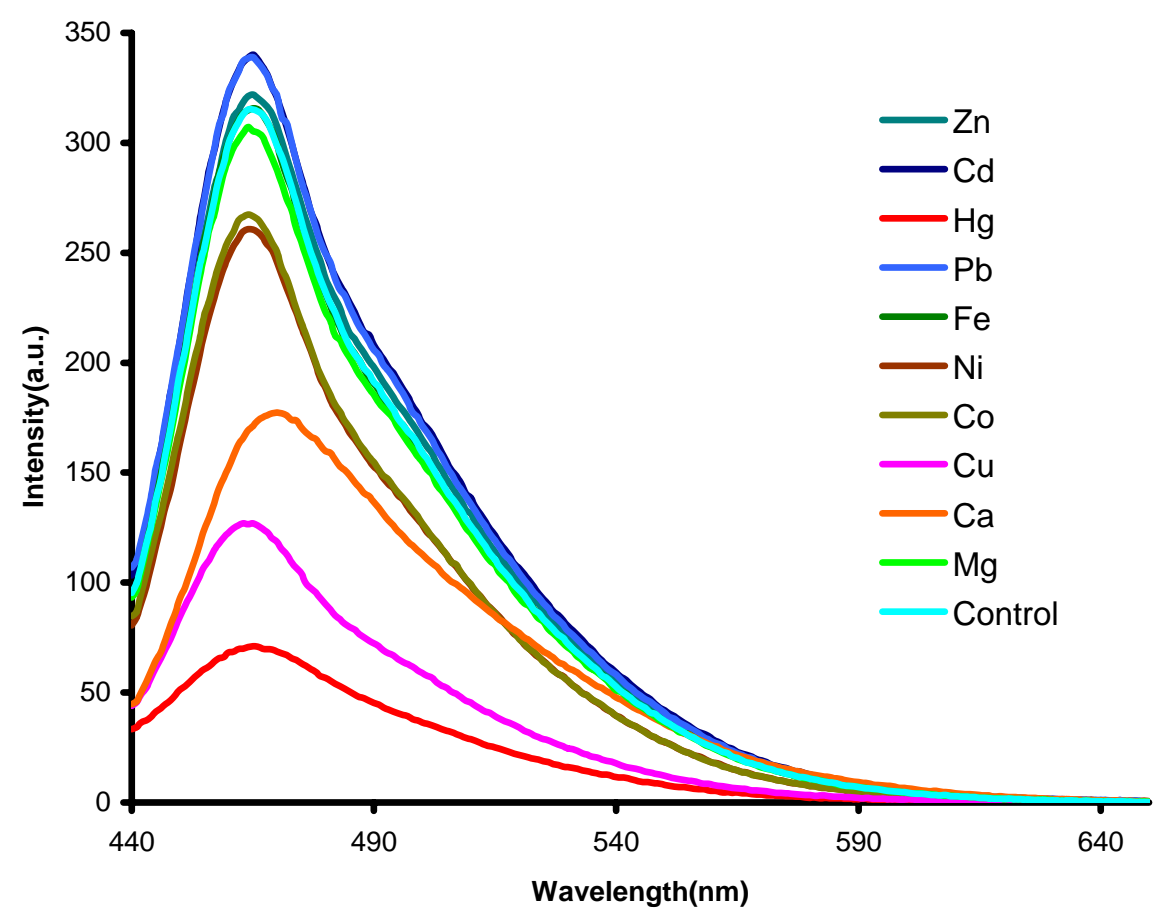

Figure 8. Emission spectra of solutions of the PPE 1-BSA complex by addition of metal ions.

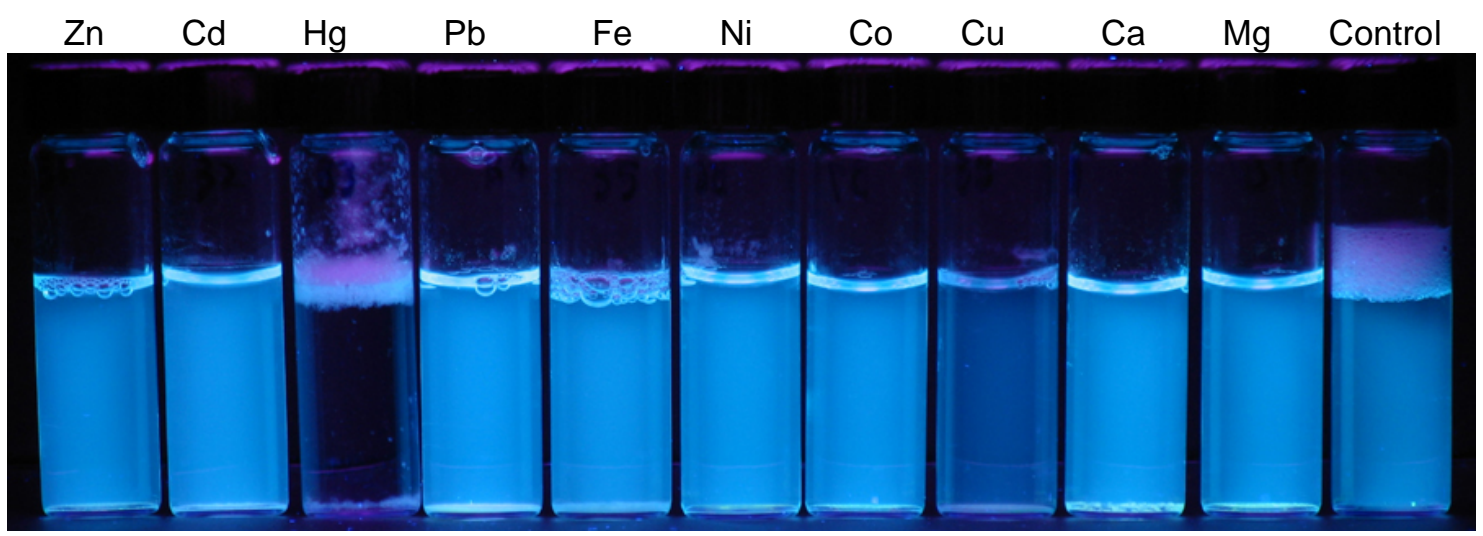

Figure 9. Fluorescence of the PPE 1-BSA complex in aqueous buffer upon addition of metal ions. (366 nm excitation) 
Exp. 2d) Influence of metal ions on the optical properties of 1 in the presence of papain.

The concentration of papain used in this experiment is $5 \times 10^{-6} \mathrm{M}$. In the PPE 1-papain complex, mercury ions led to the fluorescence quenching at the concentration of $4 \times 10^{-4} \mathrm{M}$ while most of the other metal ions show only slight quenching.

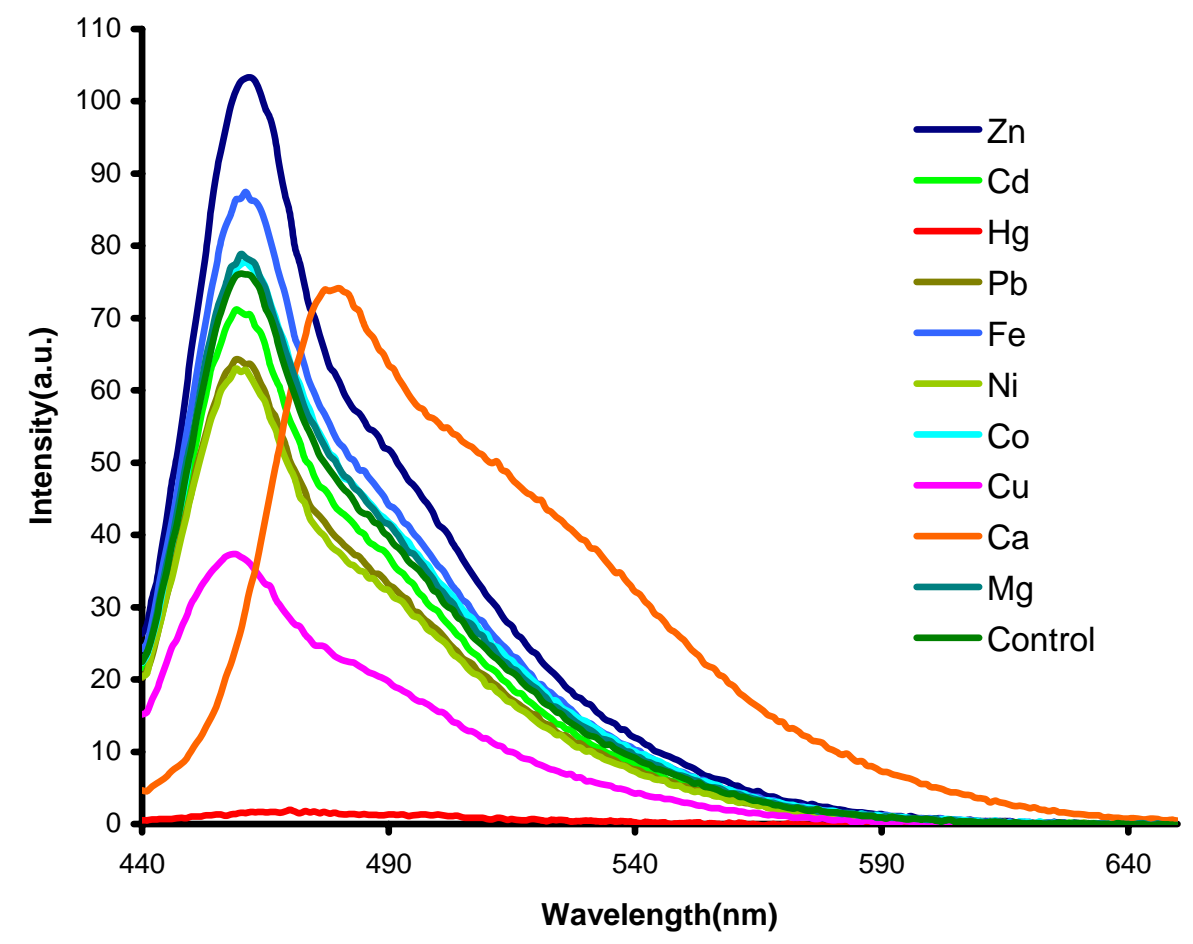

Figure 10. Emission spectra of solutions of the PPE 1-papain complex by addition of metal ions.

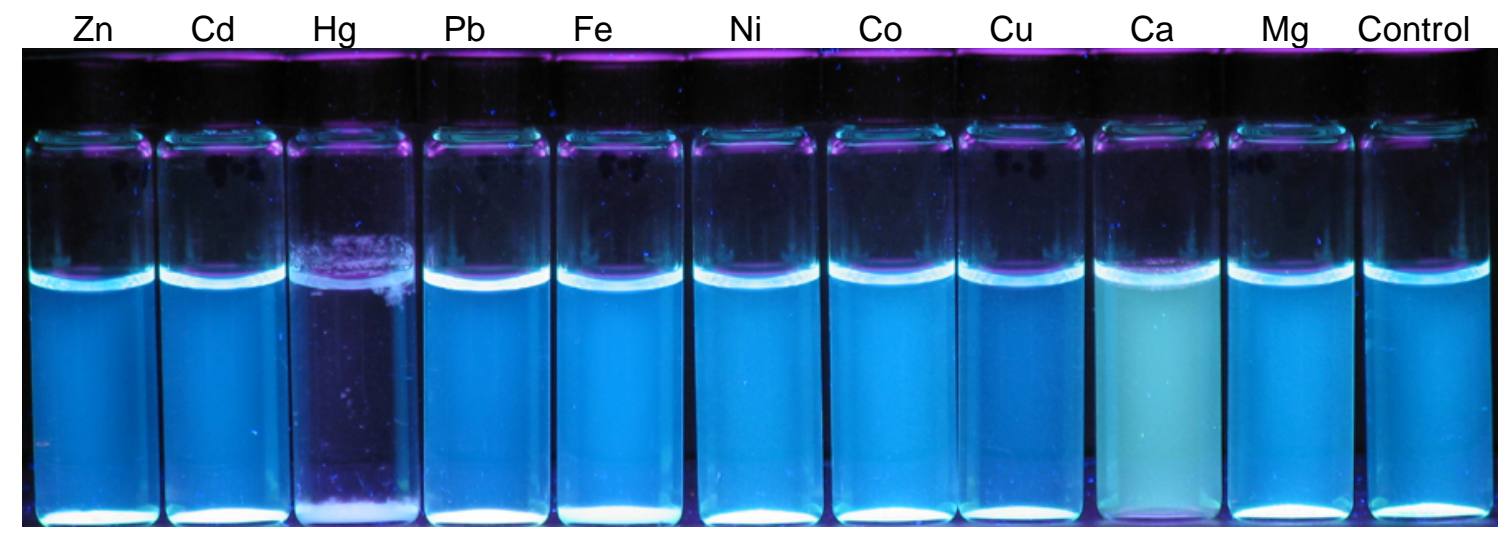

Figure 11. Fluorescence of the PPE 1-papain complex in aqueous buffer upon addition of metal ions. Ca ions show a yellow colored emission, which is consistent with its emission spectrum in Figure 10. (366 nm excitation) 
Experiment 3. Influence of polymeric and protein additives on the emissive properties of PPE 1 in the absence of metal ions.

The concentration of PPE 1 in $0.1 \mathrm{M}$ phosphate buffer solution is $5 \times 10^{-6} \mathrm{M}$ on the basis of the molecular weight of the repeating unit of PPE $\underline{\mathbf{1}}$. Concentration of each protein is $5 \times 10^{-6} \mathrm{M}$ and concentration of Pdac is $5 \times 10^{-5} \mathrm{M}$ on the basis of the molecular weight of the repeating unit of Pdac.

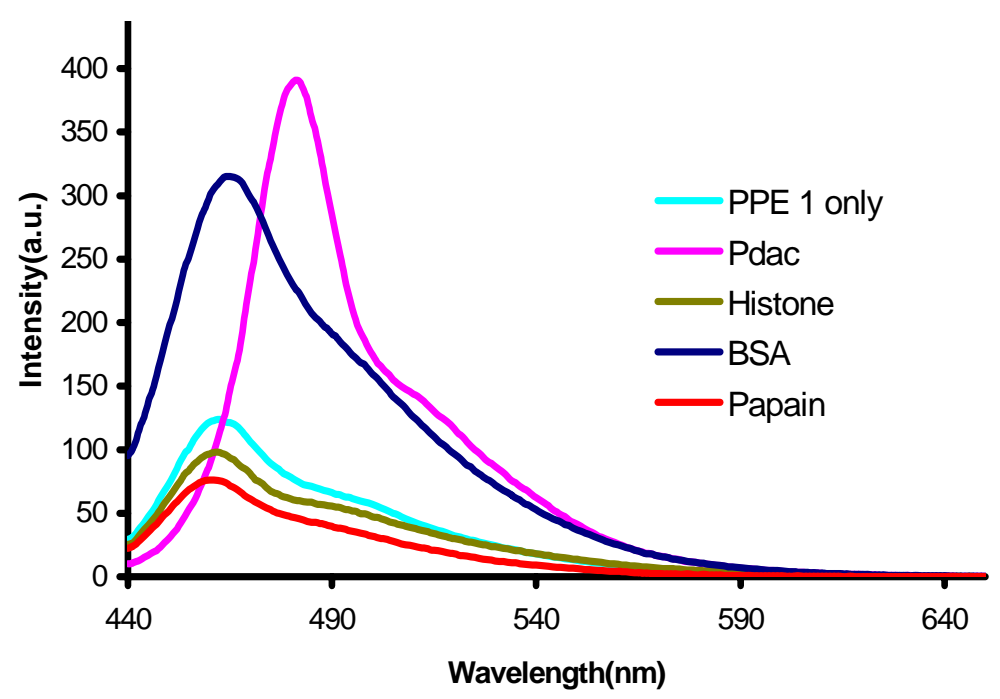

Figure 12. Emission spectra of solutions of the PPE $\underline{1}$ in the presence of polymeric and protein additives. The addition of Pdac (2) to $\underline{\underline{1}}$ leads to quenching at low molar ratio of Pdac, but an excess molar ratio of Pdac leads to increase of fluorescence of $\underline{\mathbf{1}}$ with a red shift. BSA leads to fluorescence enhancement but without shift of the emission wavelength. Histone and papain lead to aggregate with $\underline{1}$ to decrease fluorescence slightly. [Protein] $=5 \times 10^{-6} \mathrm{M}$, [PPE 1$]=5 \times 10^{-6} \mathrm{M}$, and [Pdac] $=5 \times 10^{-5} \mathrm{M}$. The concentrations of $\underline{1}$ and Pdac were calculated based on the molecular weight of the repeating unit of each polymer.

\section{Experiment 4. Concentration dependent quenching of the fluorescence of $\underline{1}$ by added mercury ions.}

Since we found that mercury ion has the most influence on the quenching of the fluorescence of $\underline{\mathbf{1}}$ at high concentrations of metal ion, we further investigated the sensitivity of $\underline{\mathbf{1}}$ by decreasing the concentration of mercury ion. The Stern-Volmer equation is the useful tool to measure the sensitivity by $\mathrm{K}_{\mathrm{sv}}$ for fluorescent conjugated polymers and fluorescent dye molecules.

$$
\mathrm{F}_{\mathrm{o}} / \mathrm{F}=\mathrm{K}_{\mathrm{sv}}[\mathrm{Q}]+1
$$

The Stern-Volmer constant is $\mathrm{K}_{\mathrm{sv}}, \mathrm{F}_{\mathrm{o}}$ is the fluorescence intensity without quencher, $\mathrm{F}$ is the fluorescence intensity with quencher at a given $[\mathrm{Q}]$, and $[\mathrm{Q}]$ is the quencher concentration. The higher value of $\mathrm{K}_{\mathrm{sv}}$ indicates the greater sensitivity of the system on the specific quencher. In this experiment, mercury ion is the quencher and we calculated the $\mathrm{K}_{\mathrm{sv}}$ values by mercury ion. In $\operatorname{PPE} \underline{1}$, the apparent Stern-Volmer constant $\left(\mathrm{K}_{\mathrm{sv}}\right)$ for $\mathrm{Hg}$ ion is $1.3 \times 10^{4}$. 


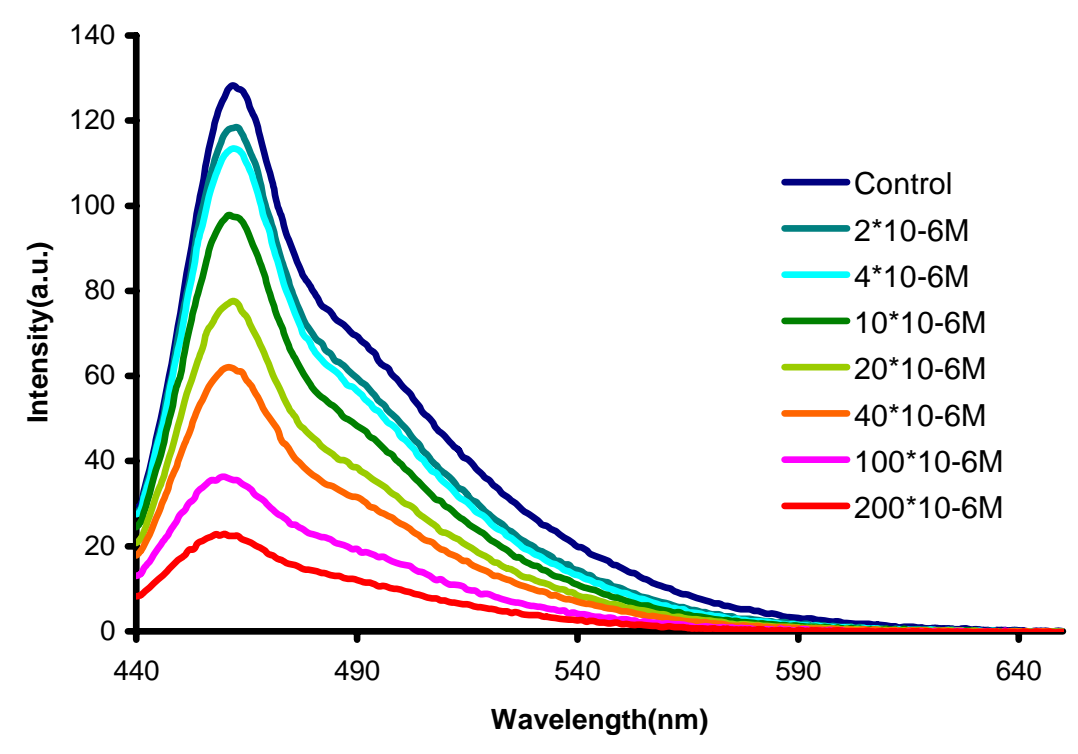

Figure 13. Emission spectra of solutions of $\underline{\mathbf{1}}$ by addition of increasing concentrations of mercury ions.

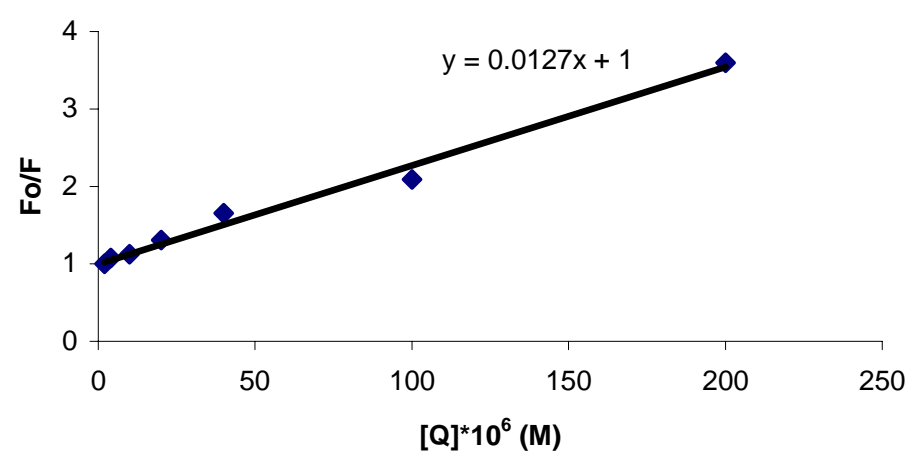

Figure 14. Fo/F plots for $\underline{\mathbf{1}}$ with mercury ions. The apparent Stern-Volmer constant $\left(\mathrm{K}_{\mathrm{sv}}\right)$ for $\mathrm{Hg}$ ion is $1.3 \times 10^{4}$.

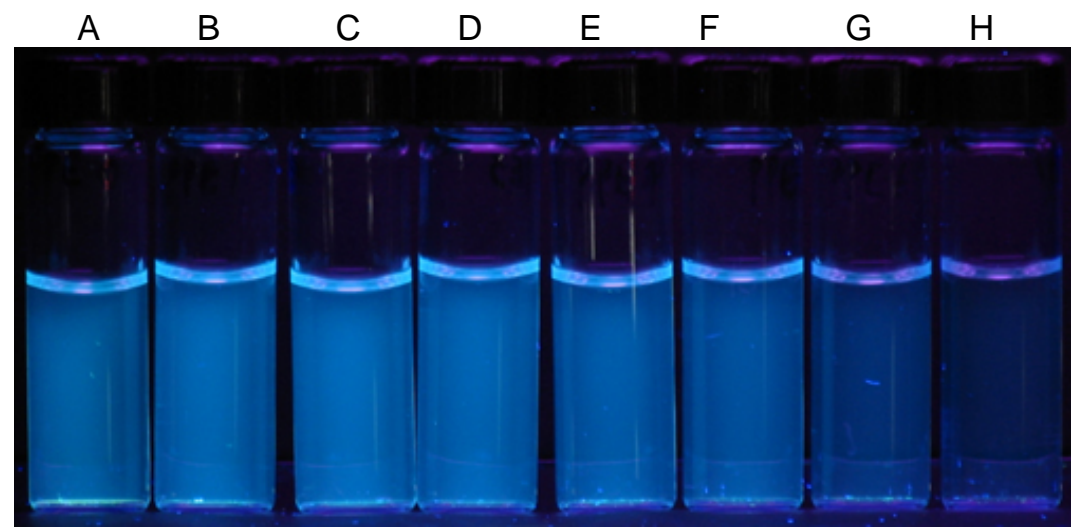

Figure 15. Fluorescence of PPE $\underline{1}$ by addition of increasing concentrations of mercury ions. A) Control (PPE 1 only), B) $\left.\left.\left.\left.\left.2 \times 10^{-6} \mathrm{M}, \mathrm{C}\right) 4 \times 10^{-6} \mathrm{M}, \mathrm{D}\right) 10 \times 10^{-6} \mathrm{M}, \mathrm{E}\right) 20 \times 10^{-6} \mathrm{M}, \mathrm{F}\right) 40 \times 10^{-6} \mathrm{M}, \mathrm{G}\right) 100 \times 10^{-6} \mathrm{M}$, and $\mathrm{H}) 200 \times 10^{-6} \mathrm{M}$. (366 nm excitation) 
Experiment 5. Concentration dependent quenching of the fluorescence of the PPE 1-BSA complex by mercury ions.

In the PPE 1-BSA complex, the apparent Stern-Volmer constant $\left(\mathrm{K}_{\mathrm{sv}}\right)$ based on the linear part of the curve is $2.0 \times 10^{4}$.

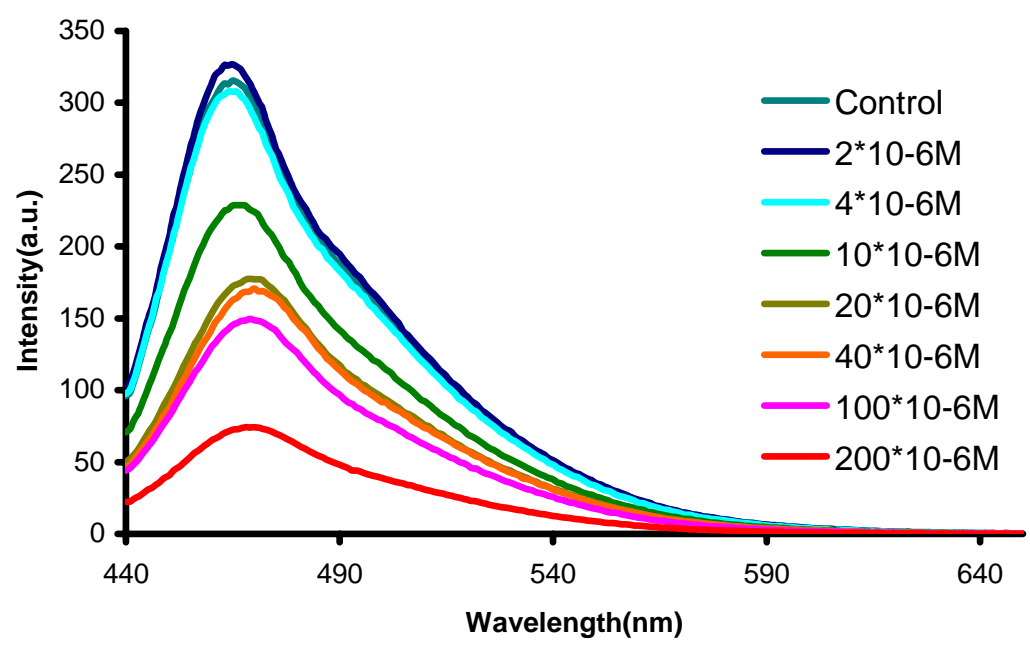

Figure 16. Emission spectra of solutions of the PPE 1-BSA complex by addition of increasing concentrations of mercury ions.
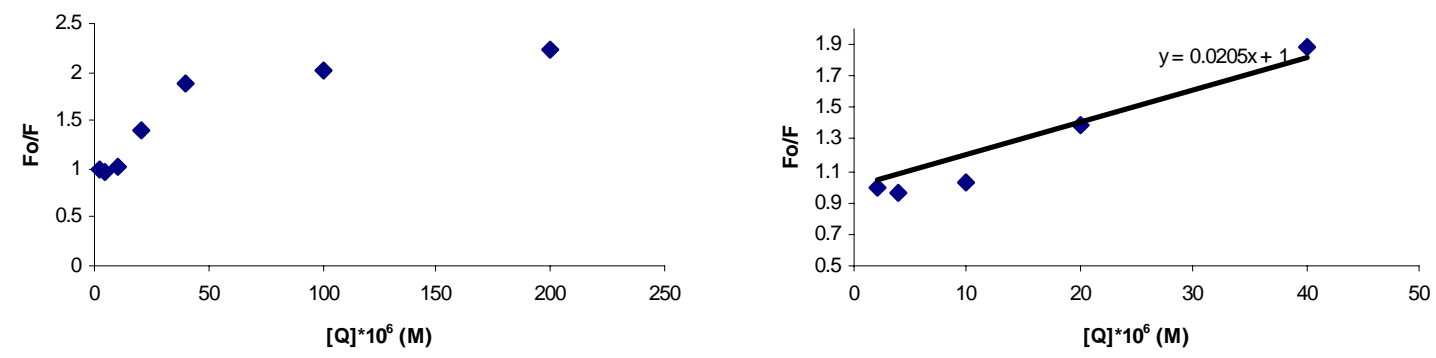

Figure 17. Fo/F plots for the PPE 1-BSA complex with mercury ions. The apparent Stern-Volmer constant $\left(\mathrm{K}_{\mathrm{sv}}\right)$ based on the linear part of the curve is $2.0 \times 10^{4}$.

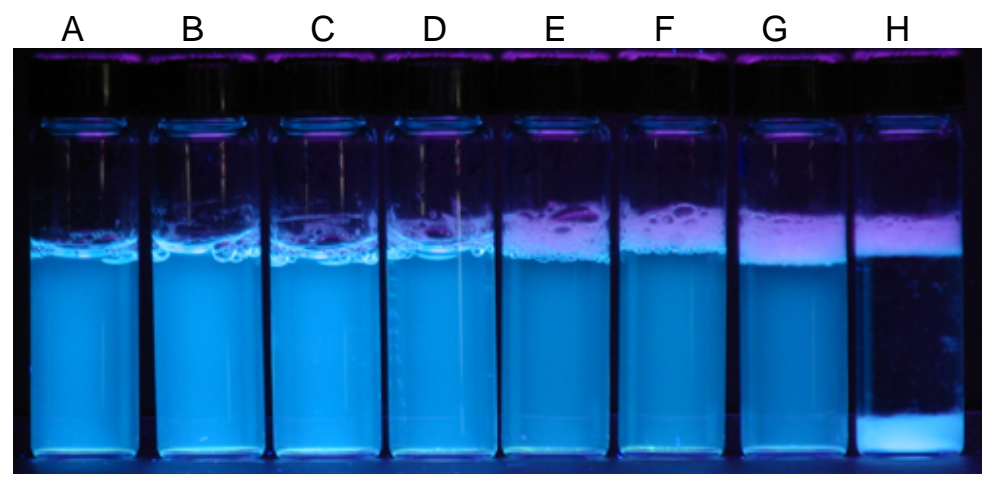

Figure 18. Fluorescence of PPE 1-BSA complex by addition of increasing concentrations of mercury ions. A) Control (PPE 1-BSA complex), B) $2 \times 10^{-6} \mathrm{M}$, C) $\left.\left.\left.4 \times 10^{-6} \mathrm{M}, \mathrm{D}\right) 10 \times 10^{-6} \mathrm{M}, \mathrm{E}\right) 20 \times 10^{-6} \mathrm{M}, \mathrm{F}\right) 40 \times 10^{-6} \mathrm{M}$, G) $100 \times 10^{-6} \mathrm{M}$, and H) $200 \times 10^{-6} \mathrm{M}$. (366 nm excitation) 
Experiment 6. Concentration dependent quenching of the fluorescence of the PPE $1-$ histone complex by mercury ion.

In the PPE 1 -histone complex, the apparent Stern-Volmer constant $\left(\mathrm{K}_{\mathrm{sv}}\right)$ for $\mathrm{Hg}$ ion is $1.6 \times 10^{5}$.

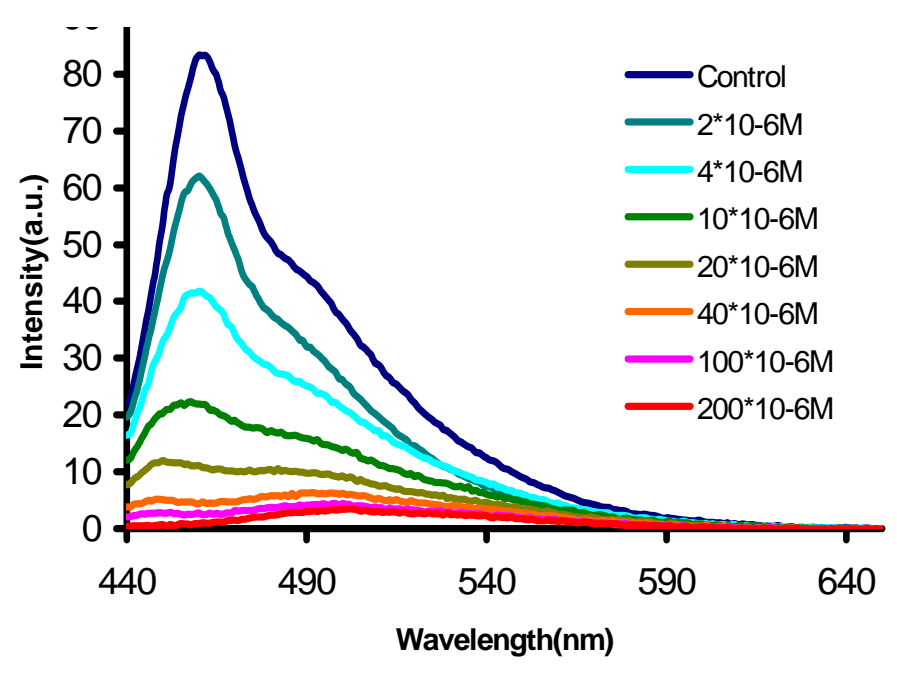

Figure 19. Emission spectra of solutions of the PPE 1-histone complex by addition of an increasing concentrations of mercury ions.

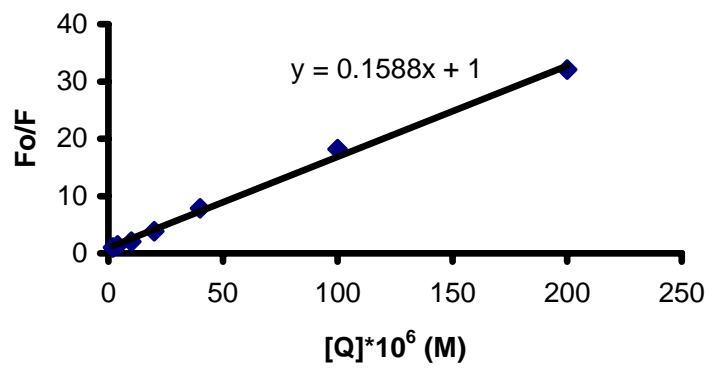

Figure 20. Fo/F plots for the PPE 1-histone complex with mercury ions. The apparent Stern-Volmer constant $\left(\mathrm{K}_{\mathrm{sv}}\right)$ is $1.6 \times 10^{5}$.

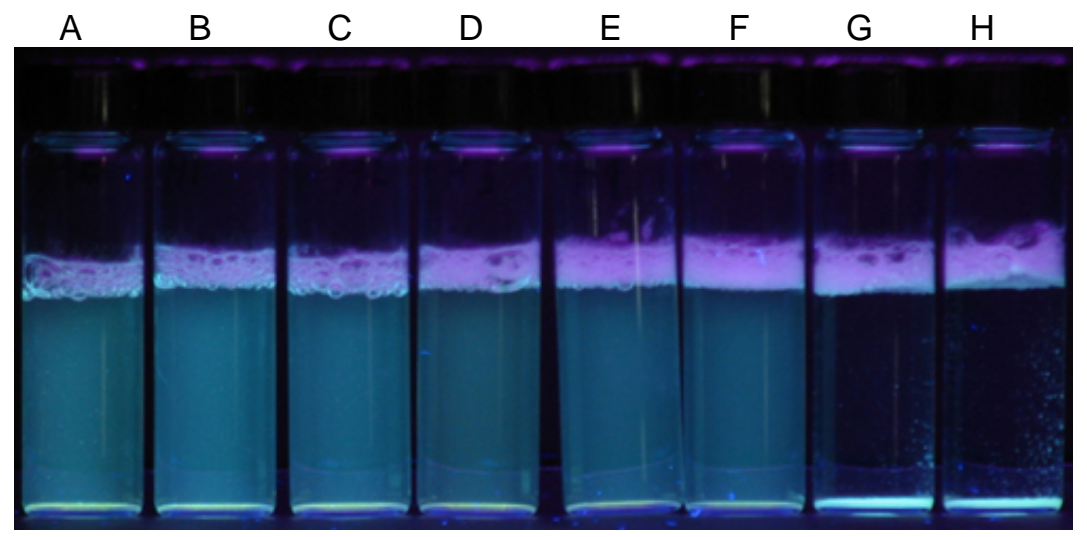

Figure 21. Fluorescence of PPE 1-histone complex by addition of increasing concentrations of mercury ions. A) Control (PPE 1-histone complex), B) $\left.\left.\left.2 \times 10^{-6} \mathrm{M}, \mathrm{C}\right) 4 \times 10^{-6} \mathrm{M}, \mathrm{D}\right) 10 \times 10^{-6} \mathrm{M}, \mathrm{E}\right) 20 \times 10^{-6} \mathrm{M}, \mathrm{F}$ ) $\left.40 \times 10^{-6} \mathrm{M}, \mathrm{G}\right) 100 \times 10^{-6} \mathrm{M}$, and H) $200 \times 10^{-6} \mathrm{M}$. (366 nm excitation) 
Experiment 7. Concentration dependent quenching of the fluorescence of the PPE $1-$ papain complex by mercury ion.

In the PPE 1 -papain complex, the apparent Stern-Volmer constant $\left(\mathrm{K}_{\mathrm{sv}}\right)$ for $\mathrm{Hg}$ ion is $5.6 \times 10^{5}$.

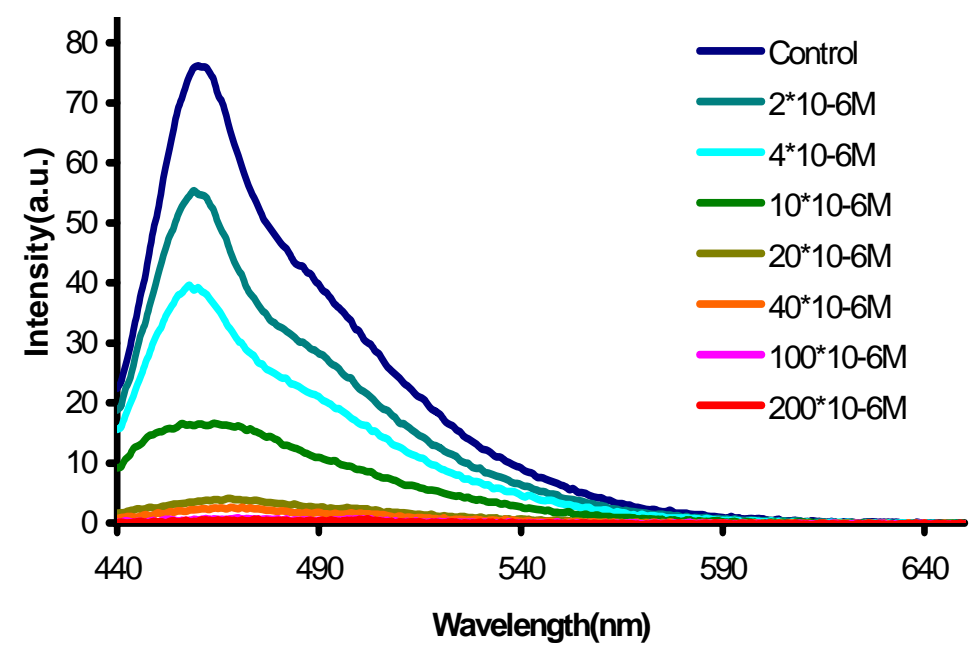

Figure 22. Emission spectra of solutions of the PPE 1-papain complex by addition of increasing concentrations of mercury ions.

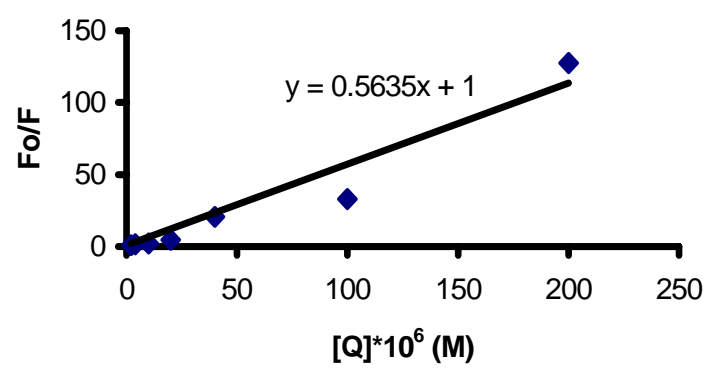

Figure 23. Fo/F plots for the PPE 1-papain complex with mercury ions. The apparent Stern-Volmer constant $\left(\mathrm{K}_{\mathrm{sv}}\right)$ is $5.6 \times 10^{5}$.

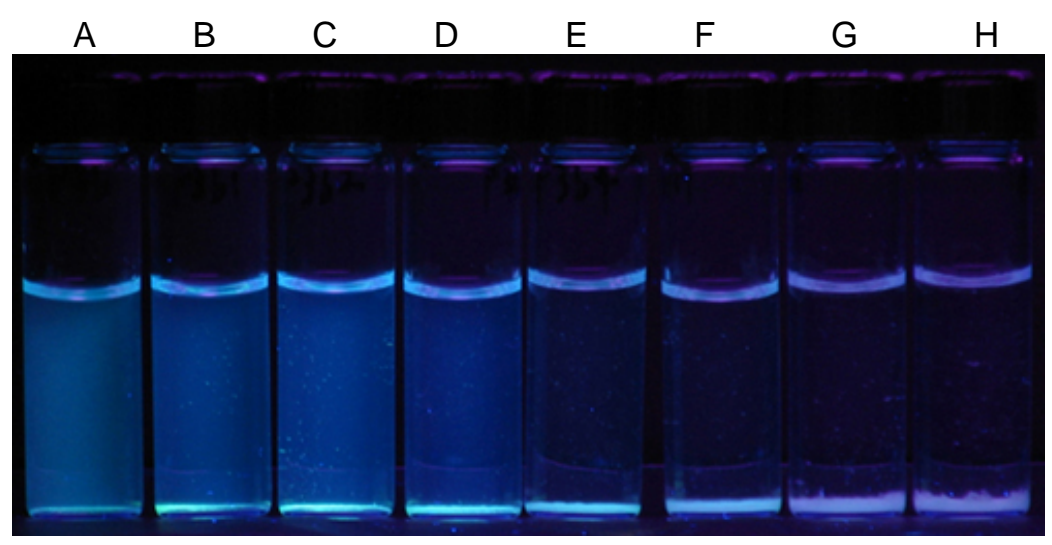

Figure 24. Fluorescence of PPE 1-papain complex by addition of increasing concentrations of mercury ions. A) Control (PPE 1-papain complex), B) $\left.\left.\left.2 \times 10^{-6} \mathrm{M}, \mathrm{C}\right) 4 \times 10^{-6} \mathrm{M}, \mathrm{D}\right) 10 \times 10^{-6} \mathrm{M}, \mathrm{E}\right) 20 \times 10^{-6} \mathrm{M}, \mathrm{F}$ ) $40 \times$ $\left.10^{-6} \mathrm{M}, \mathrm{G}\right) 100 \times 10^{-6} \mathrm{M}$, and H) $200 \times 10^{-6} \mathrm{M}$. (366 nm excitation) 


\section{Experiment 8. Selectivity of the PPE 1-papain complex for mercury ions.}

In Figure 25 and Figure 26, a comparison of the complex of $\mathbf{1}$ with papain (A), in the presence of all 10 metal cations (B), and in the absence of $\mathrm{Hg}(\mathrm{C})$ as a control, are shown. The samples (B) and $(\mathrm{C})$ are clearly different, suggesting that $\mathrm{Hg}$ can be detected in the presence of a series of other metal cations.

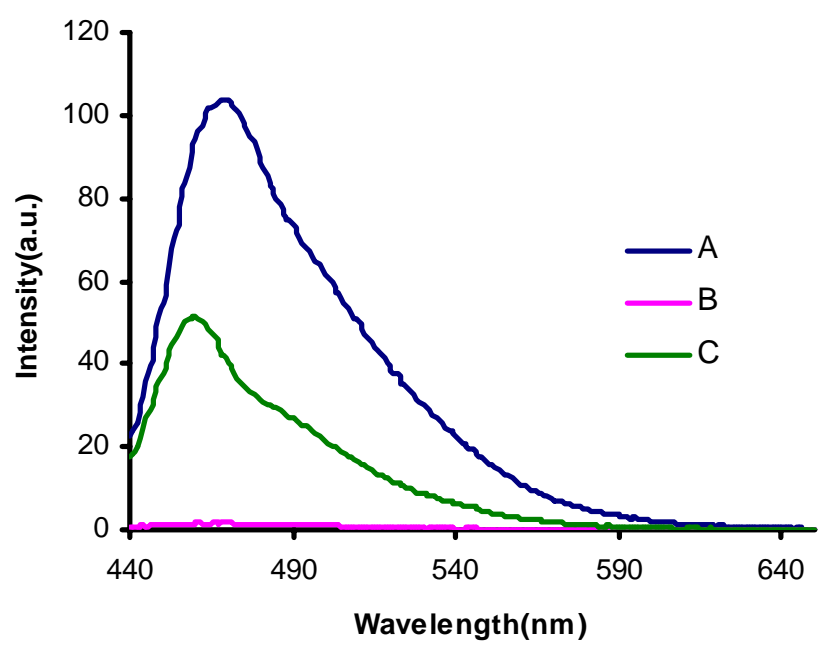

Figure 25. Emission spectra of A) PPE 1-papain complex, B) all ten metals added, C) same without Hgions. The concentration of each metal ion is $4 \times 10^{-4} \mathrm{M}$.

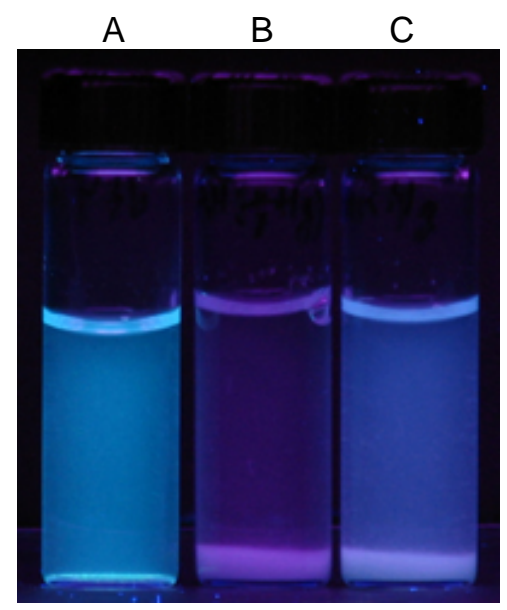

Figure 26. Fluorescence of A) PPE 1-papain complex, B) all ten metals added, C) same without Hg-ions. The PPE 1-papain Complex showed selective quenching by mercury ions in the presence of other metal cations. (366 $\mathrm{nm}$ excitation)

\section{Experiment 9. Optical Properties of the Amine-Substituted PPE $\underline{\mathbf{s}}$.}

The optical properties of the PPE $\underline{\mathbf{5}}$ in various solvents are shown in Figure 26 and Table 1. PPE $\underline{\mathbf{5}}$ has a broad absorption maximum at $431 \mathrm{~nm}$ with a shoulder near $450 \mathrm{~nm}$ in water and the emission maximum is at $458 \mathrm{~nm}$ with a shoulder near $485 \mathrm{~nm}$. The emission maximum in DMF is at $465 \mathrm{~nm}$ and slightly red-shifted. Quantum Yield of $\underline{\mathbf{5}}$ in water is $6.4 \%$ at the neutral condition $(\mathrm{pH}=7.2)$. 


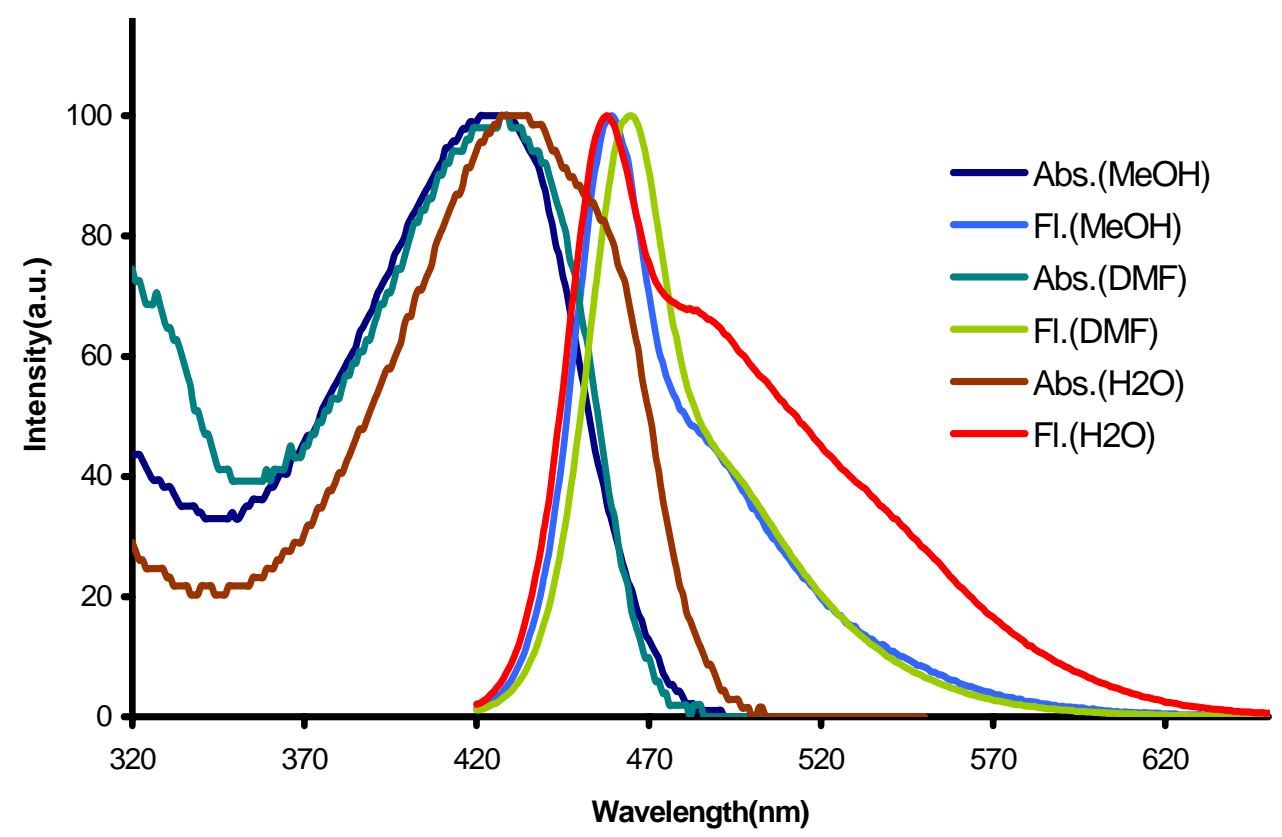

Figure 27. Absorption and fluorescence spectra of the PPE (모) in various solvents.

Table 1. Optical properties of $\underline{\mathbf{5}}$ in various solvents.

\begin{tabular}{c|ccc} 
& Abs, $\lambda_{\max }(\mathrm{nm})$ & $\mathrm{Em}, \lambda_{\max }(\mathrm{nm})$ & $\begin{array}{c}\text { Molar absorptivity, } \varepsilon \\
\left(\mathrm{M}^{-1} \mathrm{~cm}^{-1}\right)\end{array}$ \\
\hline Water & 431 & 458 & $43 \times 10^{3}$ \\
Methanol & 425 & 459 & $\mathrm{nd}$ \\
DMF & 428 & 465 & $\mathrm{nd}$
\end{tabular}

\section{Experiment 10. ATP sensing using a complex of PPE $\underline{5}$-myosin.}

Myosin is a major muscle protein consisting of skeletal muscle. Myosin has binding sites for Adenosine 5'-triphosphate (ATP) and Actin. Solutions of PPE $\underline{\mathbf{5}}$ (SS $\underline{\mathbf{5}}$ ) were prepared in $0.1 \mathrm{M}$ sodium phosphate buffer $(\mathrm{pH}=7.2)$. When myosin was added to $\underline{\mathbf{1}}$ and $\underline{\mathbf{5}}$ in buffered solutions, the optical property of $\underline{\mathbf{5}}$ was modulated, while that of $\underline{\mathbf{1}}$ was unchanged. To investigate the sensory ability of PPE $\underline{\mathbf{5}}$-myosin complex, ATP was added into a buffered solution of the complex. The emission spectra of $\underline{\mathbf{5}}$ showed a significant red shift, which suggested the formation of aggregations in moderately concentrated solutions. 


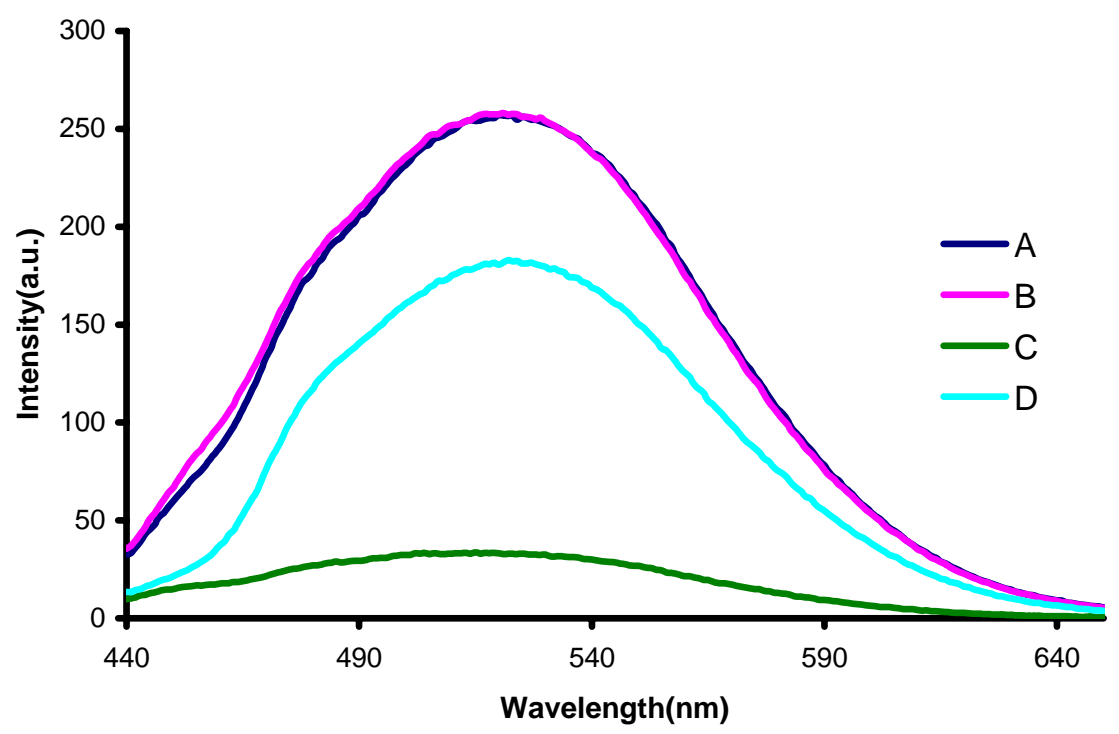

Figure 28. Emission spectra of A) $\underline{\mathbf{5}}$ only, B) $\underline{\mathbf{5}}+$ ATP, C) $\underline{\mathbf{5}}+$ Myosin, and D) $\underline{\mathbf{5}}+$ ATP + Myosin. PPE $\underline{\mathbf{5}}-$ myosin complex led to quenching of the fluorescence. In the presence of ATP $(1 \mathrm{mM})$, the fluorescence was only slightly decreased (D).

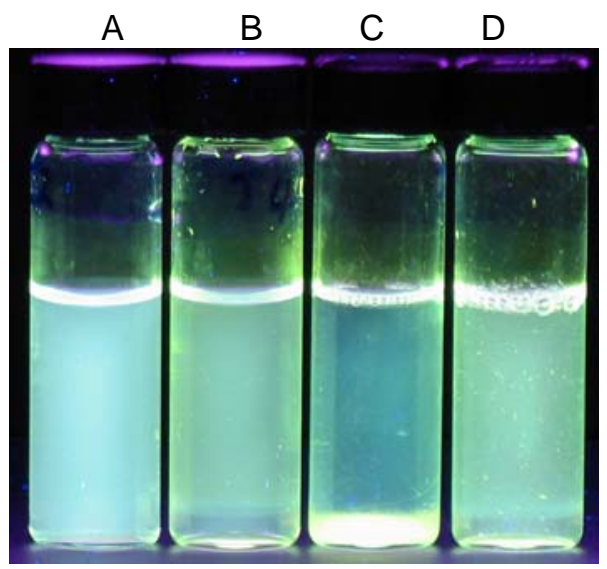

Figure 29. Addition of ATP $(1 \mathrm{mM})$ and Myosin $(0.8 \mathrm{nM})$ to solutions of PPE $\underline{\mathbf{5}}$ in 0.1.M phosphate buffer $(\mathrm{pH}=7.2)$. A) $\underline{\mathbf{5}}$ only, B) $\underline{\mathbf{5}}+\mathrm{ATP}, \mathrm{C}) \underline{\mathbf{5}}+$ Myosin, and D) $\underline{\mathbf{5}}+\mathrm{ATP}+$ Myosin. PPE $\underline{\mathbf{5}}$-Myosin complex led to a precipitate with a modification of optical property of $\underline{\mathbf{5}}(\overline{\mathrm{C}})$. In the presence of ATP $(1 \mathrm{mM})$, the complex did not precipitate out (D). Shown is the fluorescence of the solutions under a blacklight (366 nm excitation) 


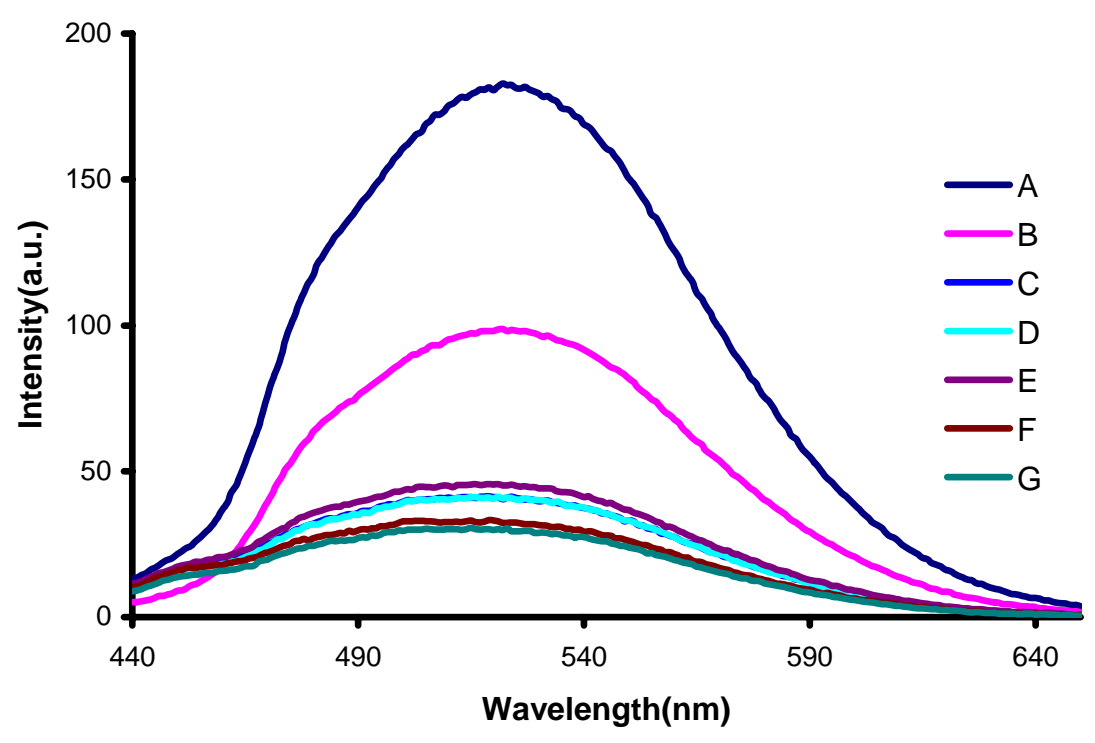

Figure 30. Emission spectra of A) $\underline{\mathbf{5}}+$ ATP $(1 \mathrm{mM})$, B) $\underline{\mathbf{5}}+$ ATP $(0.1 \mathrm{mM})$, C) $\underline{\mathbf{5}}+$ ATP $(0.01 \mathrm{mM})$, D) $\underline{\mathbf{5}}$ + ATP $(1 \mu \mathrm{M})$, E) $\underline{\mathbf{5}}+\mathrm{ATP}(10 \mu \mathrm{M}), \mathrm{F}) \underline{\mathbf{5}}+\mathrm{ATP}(100 \mu \mathrm{M}), \mathrm{G}) \underline{\mathbf{5}}+\mathrm{ATP}(1 \mathrm{nM})$. PPE $\underline{\mathbf{5}}$-myosin complex led to concentration dependent quenching of the fluorescence.

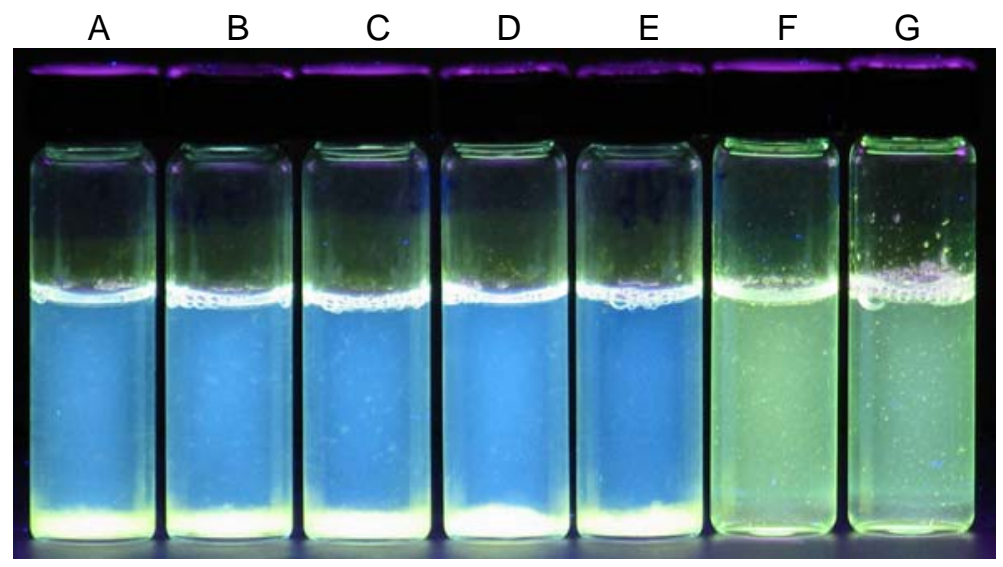

Figure 31. Addition of different amounts of ATP to solutions of PPE $\underline{\mathbf{5}}$ and myosin $(0.8 \mathrm{nM})$ in 0.1.M phosphate buffer. A) $\underline{\mathbf{5}}+$ ATP $(1 \mathrm{mM})$, B) $\underline{\mathbf{5}}+$ ATP $(0.1 \mathrm{mM})$, C) $\underline{\mathbf{5}}+$ ATP $(0.01 \mathrm{mM})$, D) $\underline{\mathbf{5}}+$ ATP $(1 \mu \mathrm{M})$, E) $\underline{\mathbf{5}}+\mathrm{ATP}(10 \mu \mathrm{M})$, F) $\underline{\mathbf{5}}+\mathrm{ATP}(100 \mu \mathrm{M}), \mathrm{G}) \underline{\mathbf{5}}+\mathrm{ATP}(1 \mathrm{nM})$. PPE $\underline{\mathbf{5}}$-myosin complex precipitated out up to $0.01 \mathrm{mM}$ of ATP and $0.1 \mathrm{mM}$ of ATP prevents the formation of precipitation. Fluorescence is shown at $366 \mathrm{~nm}$ excitation. 
Experiment 11. ATP sensing using a complex of PPE $\underline{5}$-myosin in distilled water. As a control experiment, we did same experiment with Exp. 10 in distilled water.
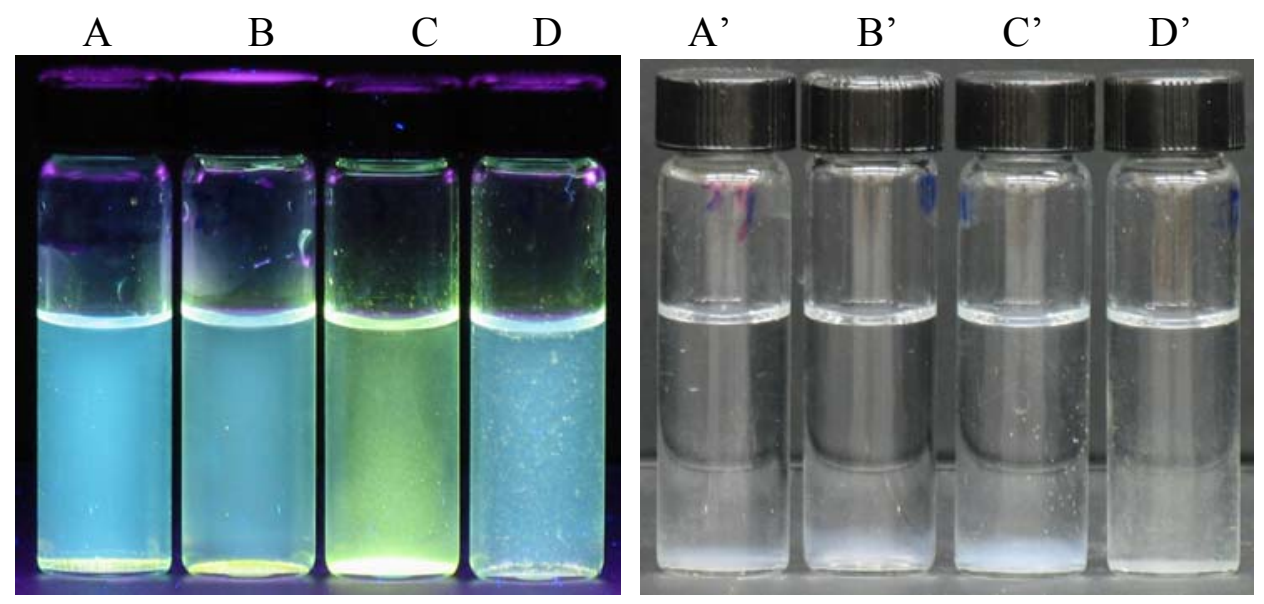

Figure 32: Left. Addition of ATP (1 mM) and Myosin (0.8 $\mathrm{nM})$ to solutions of PPE $\underline{\mathbf{5}}$ in distilled water. A) $\underline{\mathbf{5}}$ only, B) $\underline{\mathbf{5}}+$ ATP, C) $\underline{\mathbf{5}}+$ Myosin, and D) $\underline{\mathbf{5}}+$ ATP + Myosin. In distilled water, addition of myosin modified optical property of $\underline{\mathbf{5}}$ with a significant red shift while it did not change optical property in the presence of 1 mM ATP. Right. Solutions of A') Myosin in distilled water, B') Myosin in 0.1 M phosphate buffer, C') Myosin + ATP in distilled water, and D') Myosin + ATP in $0.1 \mathrm{M}$ phosphate buffer. [Myosin] $=0.8 \mathrm{nM}$, and $[\mathrm{ATP}]=1 \mathrm{mM}$. In distilled water, myosin precipitates out in the presence and absence of ATP. In $0.1 \mathrm{M}$ phosphate buffer, myosin precipitates out in the absence of ATP, while it doesn't precipitate out in the presence of ATP.

\section{Experiment 12. Flocculation of myosin in the absence of PPE $\underline{\mathbf{5}}$ (see Figure 32 Right).}

Since myosin is soluble at high salt concentration and insoluble at low salt concentration, we investigated the formation of the flocculation from Myosin in distilled water, and $0.1 \mathrm{M}$ phosphate buffer in the absence of $\underline{\mathbf{5}}$. We also investigated the effects of ATP on the formation of the flocculation from Myosin in distilled water, and 0.1 M phosphate buffer.

\section{References}

1. Kim, I. B.; Dunkhorst, A.; Gilbert, J.; Bunz, U. H. F. Macromolecules 2005, 38, 45604562.

2. Wilson, J. N.; Waybright, S. M.; McAlpine, K.; Bunz, U. H. F. Macromolecules 2002, 35, 3799-3800. 